\title{
A bird census, in Red Pine and Black Pine forests damaged by Pine Needle Gall-midges
}

\author{
Pyong-Oh Won*
}

\begin{abstract}
This bird census was conducted in red pine and black pine forests damaged by pine needle gall-midges, with a view to acquiring some knowledge of the role of the birds in these forests as predators of the larvae of these pine gall-midges.

Three areas, each having a red pine and a black pine forests, were chosen for the census: 1) an area which was suffering a very severe damage, 2) an area which was inflicted with an average degree of damage, and 3) an area which had suffered a very severe damage but seemed much recovered since then. Two forests (a red pine forest and a black pine forest) were selected from each of these three areas, which made a total of six study areas for the present census.
\end{abstract}

\section{Introduction}

Since April 1929 when some trees damaged by pine needle gall-midges were first discovered in the Secret Garden in Seoul, the infliction has gradually spread nearly all over the country at the speed of $3-5 \mathrm{~km}$ per year, and red pines are now in danagerously inflicted condition, though the degrees of damage differ from area to area. It is generally noticed that if the infliction becomes apparent to the eye in a certain area, red pines growing in that area wither to die in 4 or 5 years. Thousands of red pine trees that have withered to death are cut down every year to prevent further spread of infliction and to be replanted by trees with high immunity from insects such as Korean pines, Pinus koraiensis, and larches, Larix caempferi.

On the other hand, Jeonnam Province in the south-west part of Korea, which experienced in the past a very much severe infliction and damage, has since then shown a comparatively quick recevery and it now discloses only a very light trace of damage contrary to its past heavy infliction. Therefore it is supposed by some entomologists and ecologists that an active recovery might have taken place due to some unknown factors. They are now trying to examine the actual degree of recovery and find out the causes still unknown to them.

As a part of this effort, I have carried out a bird census in three particular areas. These areas are 1) an area which at the moment suffers a severe damage, 2) an area which is suffering an average infliction, and 3) an area which was typically inflicted with a severe damage in the past but seems fairly recovered since then. (Cf. Fig. 1) As birds usually

* Institute of Ornithology, Kyung Hee University. Seoul, Korea 


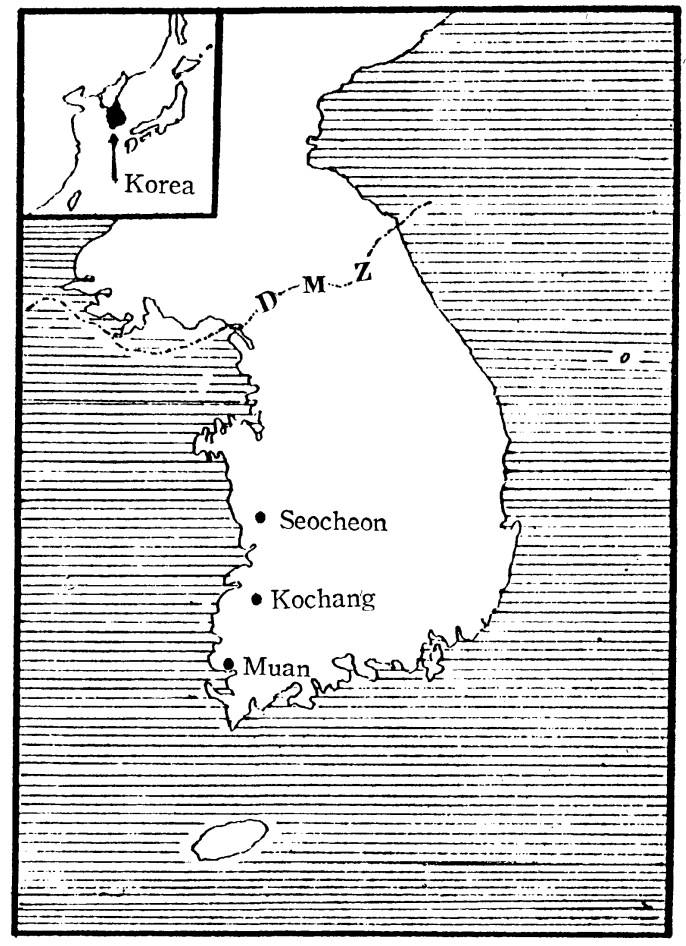

Fig. 1. Map of Census Localities. feed on the larvae of pine gall-midges when the larvae inflict damage upon pine trees in May through November, the bird census was accordingly performed within this period to trace the role of birds in the ecology of pine forests.

Mr. Moo-Boo Yoon and Mr. Taehae Koo, instructors of the Department of Biology, Kyung Hee University, have participated in this census, and four of my graduate students have assisted me throughout this census.

The census was conducted for 14 days from October 24-31, 1975 and from November 22-27, 1975 in three areas: 1) Seocheon, Chungnam Province, 2) Kochang, Jeonbuk Province, and 3) Muan-gun, Jeonnam Province. In actuality, two forests - a red pine forest and a black pine forest-were chosen from each of these three areas

for census. Hence, a total of six forests in three areas were actually covered by this census.

Two observers carried out the census by the methods of line transect and plot census in parallel, and, for reference and comparison, a quadrat census was additionally taken in the early morning once a month in each forest. In the case of line transect census, usually the observers recorded species and the number of individuals sighted within the breadth of $50 \mathrm{~m}$, $25 \mathrm{~m}$ on each side, for the distance of 2.25 to $3 \mathrm{~km}$ along the middle ridge track. In the case of plot census, the observers recorded species and the number of individuals in a unit space of 1 ha $(100 \mathrm{~m} \times 100 \mathrm{~m})$ for a total period of 120 minutes ( $30 \mathrm{~min} . \times 4$ times, in succession). In the case of quadrat census, the observers recorded species and the number of individuals in a space of $4,000 \mathrm{~m}^{2}(50 \mathrm{~m} \times 80 \mathrm{~m})$ for a 20 -minute unit in the early morning. This was performed only twice (once in each month) to observe birds that occur in the early morning.

Thus, the line transect census was carried 12 times -2 times (once a month) in each of the six forests 3 areas; the plot census was performed 12 times, each time for 120 minute, in the same six forests.

The results of the census were computed to get the relative density and dominance of each species per kilometer, hour and hectare, and then from these figures, the overall density of bird population in each forest for each month was computed and compared. In addition, I have made an attempt at calculating the feeding density at birds as follows : 


$$
\text { F. D }=\frac{\mathrm{N}}{\mathrm{H} . \mathrm{S}} \times \text { h. a }
$$

where, S: Plot size

$\mathrm{H}$ : Observation hours

$\mathrm{N}$ : The number of birds that arrived in $\mathrm{S}$

$\mathrm{h}$ : Unit hour $(1 \mathrm{~h})$

a: Unit space (1 ha)

In order to acquire a comprehensive knowledge of the bird species in these areas, the present census included in its record all the birds sighted in the areas, whether they stayed in, flew over or made a transit through these areas. As this kind of bird census is usually performed with a good result early in the morning, the present census was mainly conducted from before dawn to about 10 a. $\mathrm{m}$.

Since the ideal walking speed in a line transect census is 1.7 to $2.0 \mathrm{~km} / \mathrm{hr}$, on the average, a distance of 3.5 to $4 \mathrm{~km}$ may well be continuously walked, but our line transect census was usually conducted for a distance of 2.25 to $3 \mathrm{~km}$ (with an average distance of $2.68 \mathrm{~km}$ ) on account of the lack of continuous forest areas over $3 \mathrm{~km}$ in length.

The plot census lasted each time for 120 minutes (with 4 thirty-minute units in succession), which was sufficient for making the record of birds sighted in a given area, but no distinction was made in the record between those birds which visited the area or their feeding density, and other birds which just flew over the area. This, I regret, should have been made with such divisions as 'flying', 'call', 'song', 'visual', and so on.

The quadrat census should have been independently conducted from the line transect census for about 2 hours (with 20-minutes units) at least 4 times, but it was in effect performed once a month. This barely enabled me to make a comparison of the results of the census for the early morning with those for the late morning.

Future censuses should be conducted by the three methods mentioned above for the same period at least twice a month with due measures and considerations. Monthly censuses in each season should also be taken, and in summer a breeding bird census should be performed.

\section{Result and consideration}

\section{Seocheon Area}

The forest in this area suffers a very severe damage by pine needle gall-midges.

\section{Red Pine Forest}

The distance covered by the line transect census is about $3 \mathrm{~km}$, and the observation space is about 15 ha. The forest is located around Heungrim reservoir and the red pine forest stretches from the Janghang railway to the north-east of the reservoir along the railway running round the reservoir to its south-west. This forest consists mainly of red pines of 15 to 20 years old. The areas for plot census and quadrat census are near the south end of Heungrim village. (Cf. Fig. 2) 
The result of the line transect census shows a decrease in the number of the species from 20 in October to 18 in November, while it represents an increase in the number of individual birds from 378 in October to 590 in November. This is because in October many bird species, such as Bush warbler, Black-faced bunting and Tristram's bunting, usually come down to this area from the north, and in November comparatively large flocks of winter visitors such as Brambling, Siskin and Rustic bunting appear. This makes an increase in the number of species in October while the number of total individual birds is comparatively small in November.

In October, Great tit is the most dominant species which occupies $(17.72 \%)$ and then

Red Pine Wood

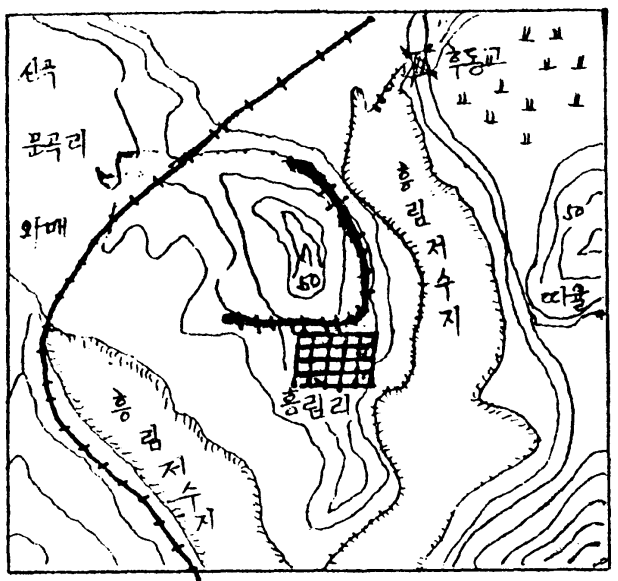

Fig. 2 .
Black Pine Wood

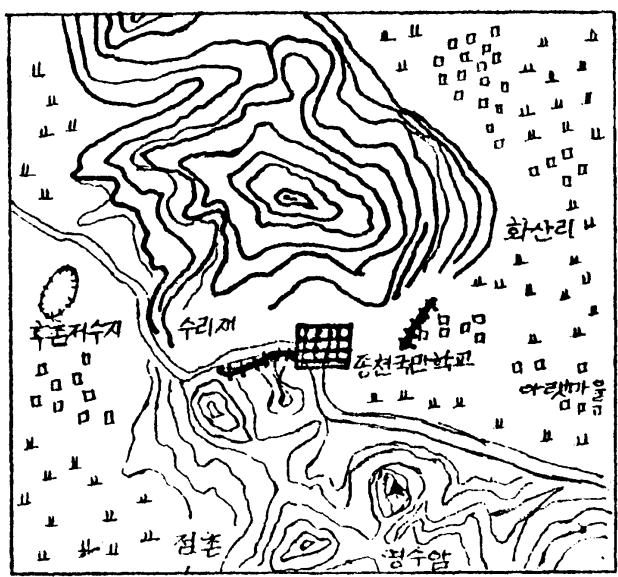

Fig. 3.

Seocheon area

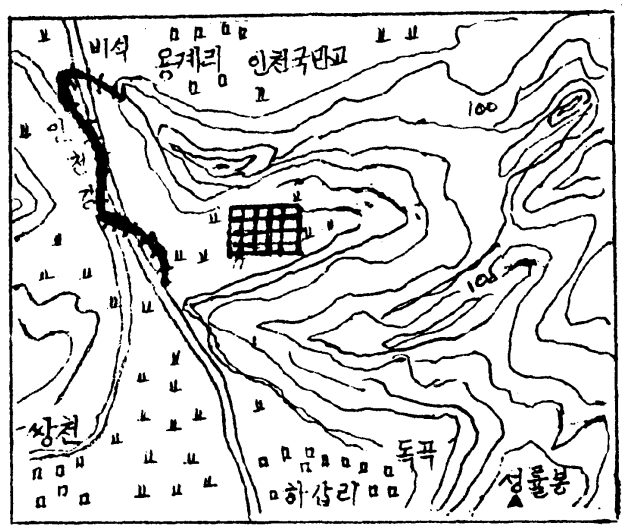

Fig. 4 .

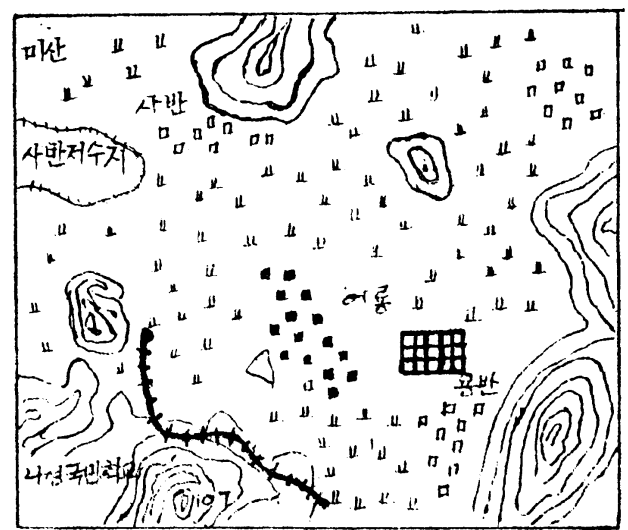

Fig. 5.

Line Transect

Fig. 2-5. Sketch Map of Study Areas. 
Kochang area

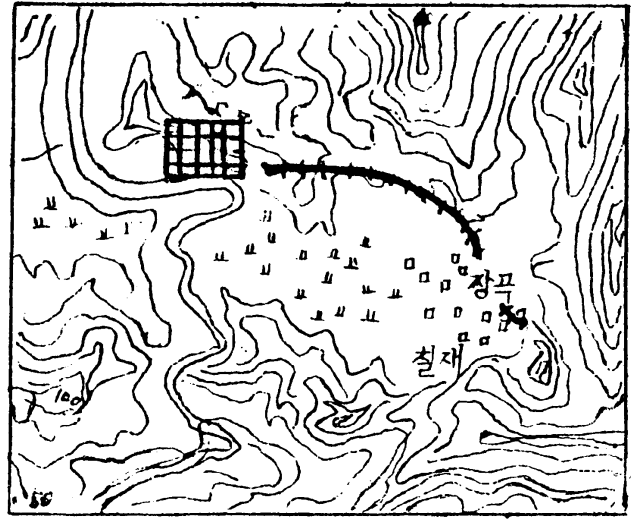

Fig. 6 .

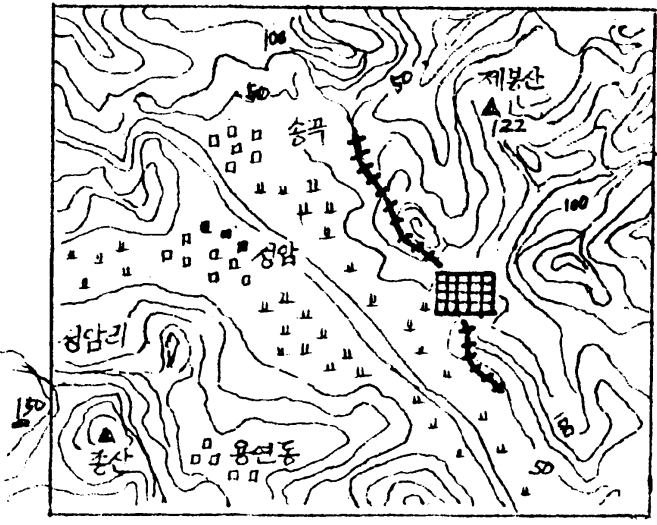

Fig. 7 .

Muan area

HH111+H Line Transect

Plot Census

Fig. 6-7. Sketch Map of Study Areas.

follow Yellow-throated bunting $(16.40 \%)$, Crow tit $(15.60 \%)$, Turtle dove and Jay (each 8.99\%). These 5 species of permanent residents take $67.70 \%$ of the total recorded individuals in this area. In November, Turtle dove occupies $30.16 \%$, and then follow Great tit and Brambling (each 12.03\%), Siskin (10.50\%), Yellow-throated bunting (10.33\%), Crow tit $(5.25 \%)$ and Jay $(4.91 \%)$, and these 7 species take $85.21 \%$ of the total recorded individuals in this area. In this way, a change among dominant species has occurred because winter visitors of Siskin and Brambling have come down. Although permanent residents of Great tit, Turtle dove, Yellow-throated bunting, Jay, Crow tit, etc. have a variation in their species dominance, they are in fact typically dominant species in this area. Dusky thrush makes a transit across this area both in October and November, but only a few Rustic buntings come down to this area before the end of November.

The plot census shows a more or less similar tendency. That is a change from 14 species with 215 individuals in Octover to 13 species with 451 individuals in November. Dominant species in October are Great tit (47.44\%), Jay $(27.44 \%)$, Turtle dove $(6.52 \%)$ and Crow tit $(4.65 \%)$, and those in November are Siskin $(55.21 \%)$, Brambling $(22.40 \%)$, Turtle dove $(5.99 \%)$, Crow tit $(4.43 \%)$ and Great tit $(3.55 \%)$, this result is similar to the case of the line transect census performed in the same area. However, there is a difference. It is the fact that in the line transect census 19 species were sighted in October and November, while in the plot census only 11 species were observed during the same period. This difference must be due to the environmental difference in the areas for the census and it must also depend on the frequency with which birds are encountered. 
In the early morning quadrat census, 11 species with 155 individuals are sighted during the 20 minute period from 7:30 7:50 a.m. in October, and 8 species with 41 individuals during the 20 minute period from 8:00 to 8:20 a.m. in November, while on the other hand, in the plot census only 6 species with 54 individuals are observed during the 30 minute period from 10:00 to 10:30 a. m. in October and only 5 species with 44 individuals during the 30 minute period from $9: 50$ to $10: 20 \mathrm{a} . \mathrm{m}$. in November. This shows that the earlier the time is, the more species and individuals are sighted.

\section{Black Pine Forest}

The distance covered in the line transect census in this area is about $2.25 \mathrm{~km}$, and the observation space is about 11.25 ha. This area stretches from Witsaem village to the top of a hill over Surineumeo-jae at the eastern tip of the slope at the back of Jongcheon Primary School in Jongcheon-myeon, and the census is conducted along a road running in parallel with the old Main Road from Seoul to Busan. Though black pine trees of 30 to 40 years old line up continuously in this area, the forest is comparatively poor. The areas for the plot census and the quadrat census are the southern slope of the old Main Road near the hill over Surineumeo-jae. (Cf. Fig. 3.)

In the line transect census, 16 species with 186 individuals were sighted in October and 9 species with 461 individuals were observed in November. As for the dominant species in October, Great tit $(22.58 \%)$ is the most dominant and then follow Greenfinch $(17.74 \%)$, Yellow-throated bunting (12.36\%), Turtle dove (11.29\%) and so on. These 4 species occupy $63.97 \%$ of the total individual birds sighted in this area. In November, Brambling $(61.38 \%)$ is the most dominant, and then follow Siskin (18.87\%), Great tit (9.97\%), Yellow-throated bunting (4.98\%), etc. These 4 species take $95.20 \%$ of the total individual birds sighted.

The result of this census performed in the black pine forest discloses a tendency which is more or less similar to the one that has been mentioned in the case of red pine forest. While there is a decrease in the number of the species sighted from 16 in October to 9 in November, the number of the individual birds sighted increases from 186 in October to 461 in November. This is chiefly due to the fact that, while in October such transients as Black-faced bunting, Chestnut bunting and Olive-backed (or Indian tree) pipit affect this area, in November large flocks of winter visitors such as Siskin and Brambling come down to this area. Though the number of the species sighted in October is smaller, the dominant species, Great tit, Yellow-throated bunting, Turtle dove and Jay are the permanent residents of both red pine and black pine forests, and Siskin (17.74\%) alone is a dominant species in the black pine forest. Again, though the number of the species sighted in November is smaller, the dominant species are, as in the case of the red pine forest, winter visitors such as Brambling and Siskin and permanent residents such as Great tit and Yellow-throated bunting.

Though in the plot census there is also a decrease in the number of the species observed from 14 to 10 , the number of the individuals sighted increases from 268 in October to 840 
in November. This is because while transients such as Chestnut bunting, Black-faced bunting, Olive-backed pipit, Chinese grosbeak and Woodcock, temporarily occur in October, as in the case of the red pine forest, large flocks of Brambling and Siskin arrive in this area in November.

On the other hand, in the early morning quadrat census, 5 species with 198 individuals were sighted during the 20-minute period from $8: 00$ to $8: 20 \mathrm{a} . \mathrm{m}$. in October and 8 species with 45 individuals during the 20-minute period from $7: 10$ to $7: 30 \mathrm{a} . \mathrm{m}$. in November, while in the plot census 6 species with only 104 individuals were sighted during the 30minute period from 9:20 to 9:50 a. m. in October, and in November as many as 10 species with 65 individuals were observed during the 30-minute period from 9:00 to 9:30 a.m. This sort of change depends upon whether or not there is an encounter with a large flock of birds such as Brambling or Siskin in their wandering flight, and upon several species each of which comprises a single bird recorded such as Siberian bluechat, Chestnut bunting and Goshawk.

\section{Kochang Area}

The forest in this area suffers an average damage by pine needle gall-midges.

\section{Red Pine Forest}

The distance covered by the line transect census is about $2.5 \mathrm{~km}$, and the observation space is about 2.5 ha. This forest is a slope stretching from Incheon Primary School, Yongge-ri, Asan-myeon to the south of Hagap Bridge, with red pines of an average height of about $3 \mathrm{~m}$, and of 15 to 30 years old. The areas of the plot census and the quadrat census are the southern slope near Dokgok in Hagap-ri. (Cf. Fig. 4)

In the line transect census, 14 species with 374 individuals and were sighted in October and 13 species with 369 individuals in November. The most dominant species in October is Siskin (29.14\%), and then it is followed by Brambling (26.73\%), Great tit (25.13\%), Crow tit (9.09\%) and so on. These 4 species occupy $90.09 \%$ of the total individuals recorded in this area. The most dominant species in November is Siskin (33.06\%) followed by Brambling (20.86\%), Great tit (13.27\%), Crow tit (8.13\%) and so forth. These 4 species take $75.32 \%$ of the total individual birds sighted in this area.

Though there is a small change in their percentage between October and November, no difference is seen in the dominant species themselves between October and November; also there is little difference between October and November in the number of species and individuals sighted in this area. All the birds sighted in this area, except winter visitors such as Siskin and Brambling and transients such as Dusky thrush and Olive-backed pipit, are residents of this area.

The census results which show almost no difference between October and November are on account of the arrival of the winter visitors, Siskin and Brambling, when the temperature went down around the 31 st of October on which the census was taken. While the census was going on from the 24 th through the 31 st of October, the cold weather suddenly set in 
and lasted for a few days in this area.

In the plot census, 16 species with 507 individuals were sighted in October, and 8 species with 266 individuals in November. In October, Brambling occupies 36.67\%, which is the most dominant, followed by Great tit (27.02\%), Siskin (21.89\%), and so on. These 3 species occupy $86.58 \%$ of the total individuals sighted in this area. In November, the most dominant species is Great tit (34.96\%) followed by Brambling and Goldcrest (each 18.79\%), Siskin $(13.15 \%)$ and so forth. These 4 species occupy $85.69 \%$ of the total individuals sighted in this area. The fact that more species were sighted in October than in November is largely due to the observation of common residents usually made up of several individuals such as Jay, Meadow bunting, Ring-necked pheasant, Turtle dove, Bull-headed shrike, Greenfinch, Longtailed tit, Wren and so on, apart from migrants such as Hawfinch, Olive-backed pipit, Dusky thrush, etc. Besides, on the 31st of October, when the temperature suddenly went down, large groups of Siskin and Brambling were passing through this area.

\section{Black Pine Forest}

The distance of the line transect census is about $2.75 \mathrm{~km}$, and the observation space is about 13.75 ha. The census area is the northern and eastern slopes stretching from the hill between Eoyong-ri and Saban-ri to the Saban reservoir, crowded with tall black pine trees 25 to 35 years old. The areas of the plot census and the quadrat census are the eastern slope at the east of Eoyong-ri. (Cf. Fig. 5)

In the line transect tensus, 16 species with 306 individuals were sighted in October and 12 species with 159 individuals in November. The most dominant species in October is Siskin (25.49\%), followed by Greenfinch (19.28\%), Great tit (17.97\%), and so on. These 3 species occupy $62.74 \%$ of the total individuals sighted in this area. In November, the most dominant species is Great tit $(27.51 \%)$, followed by Siskin $(17.98 \%)$, Yellow-throated bunting (16.40\%), Brambling (10.58\%) and so on. These 4 species take $72.47 \%$ of the total individuals sighted in this area. The reason why more species of birds were sighted in October than in November is, as in the case of the red pine forest, that transients such as Dusky thrush, Black-faced bunting and White wagtail arrived there in October, and the reason why more individual birds were sighted in October than in November is that the observers encountered large flocks of Crow tit, Greenfinch, Meadow bunting and Turtle dove in October, and not in November. Repeated censuses may eliminate such a distinction.

In the plot census, 12 species with 385 individuals were sighted in October and 10 species with 590 individuals in November. The most dominant species observed in October is Siskin $(71.92 \%)$, followed by Greenfinch $(18.44 \%)$, Turtle dove $(7.53 \%)$, Great tit $(6.75 \%)$ and so on. These 4 species occupy $98.15 \%$ of the total individuals sighted in this area. The most dominant species in November is Siskin $(77.11 \%)$, followed by Great tit $(8.13 \%)$, Brambling (4.91\%), and so on. These 3 species occupy $90.15 \%$ of the total individuals sighted in this area. More species of birds were sighted in October than in November, due to the presence of transients such as Hawfinch and Olive-backed pipit, but the number of 
individual birds sighted in November is much larger than that in October. This is because large flocks of Siskin and other flocks of Goldcrest and Brambling arrived in this area in November.

III. Muan Area

The forest in this area suffered a very severe damage by pine needle gall-midges in the past, but the damage it is suffering now seems very light. This makes us presuppose some unknown factors which might have had an contributory effect on the gradual recovery of the forest.

\section{Red Pine Forest}

The distance of the line transect census is about $2.75 \mathrm{~km}$, and the observation space is about 13.75 ha. The area lies around Janggok (Janggol) village, Jisan-ri, Samhyang-myeon, with a forest of red pine trees 20 to 30 years old. The areas of the plot and the quadrat censuses are the southern slope in front of Janggok village. (Cf. Fig. 6)

In the line transect census, 19 species with 255 individuals were sighted in October and 17 species with 278 individuals in November. The most dominant species in October is Chestnut bunting $(20.78 \%)$, followed by Great tit (14.11\%), Siskin (11.76\%), Crow tit $(7.84 \%)$ and so on. These 4 species occupy $54.49 \%$ of the total individuals sighted in this area. The most dominant species in November is Siskin $(35.61 \%)$, followed by Crow tit $(19.06 \%)$, Great tit $(11.15 \%)$, Jay $(8.63 \%)$ and so on. These 4 species occupy $74.45 \%$ of the total individuals sighted in this area.

It is peculiar that Chestnut bunting was the most dominant among all the species sighted in October. In fact, many flocks of Chestnut bunting were feeding in millet farms near the census area. Again, that the number of species and individuals sighted in October is larger than those sighted in November is due to the passing through the area of several species of transients such as Black-faced bunting, Chestnut bunting and Tristram's bunting that usually migrate southward through the southwestern province of Korea.

The plot census records 16 species with 166 individuals in October and 14 species with 390 individuals in November. Great tit $(37.35 \%)$ is the most dominant species in October and the next is Crow tit $(22.90 \%)$, followed by Yellow-throated bunting and Tristram's bunting (each 6.02\%) and so on. These 4 species are dominant in this area in October. On the other hand, in November Brambling (38.62\%) is the most dominant, followed by Siskin $(32.48 \%)$, Crow tit $(7.67 \%)$, Great tit $(6.13 \%)$ and so on. These 4 species are dominant in this area in November and occupy $84.90 \%$ of the total individuals sighted in this area.

Among the species sighted in October, Bush warbler is a summer visitor and other species of transients such as Black-faced bunting, Chestnut bunting and Tristram's bunting are migrants. All of these pass through the south-western province of Korea in October. Though these transients are not seen in November, flocks of winter visitors such as Siskin and Brambling come down from the north, and the number of individual birds increases 
in November.

Between the line transect and the plot censuses there are differences in the most dominant species and species dominance, but there is a similarity in that the same bird species become dominant both in October and November. Though in October Chestnut bunting and Tristram's bunting were dominant, in November large flocks of Siskin and Brambling arrived in this area. Great tit, Crow tit, Jay and Yellow-throated bunting are dominant residents in this area.

\section{Black Pine Forest}

The line transect census distance is about $2.88 \mathrm{~km}$, and the observation space is about 14.40 ha. This area is the black pine forest that is the heaviest among the six census areas, and it is the southern slope along the road from the reservoir at the east of Seongam-ri at the southmost end of Wumyeong Mountain in Sachang-ri to the Seongam hill. (Cf. Fig. 7)

The plot and the quadrat census areas are a slope between Songgok and Wumyeong Mountain, which is the south slope to the north-east of Seonggok village. The total birds sighted in the two censuses in October and November are 15 species with 289 individuals. Among these, 14 species with 215 individuals were sighted in October, and 11 species with 159 individuals were sighted in November.

In October, Chestnut bunting $(38.13 \%)$ is the most dominant species, followed by Siskin (15.81\%), Great tit (11.62\%), and so on. These 3 species occupy $65.56 \%$ of the total individuals sighted in this area. In November, Siskin (33.33\%) is the most dominant species, followed by Great tit $(27.67 \%)$, Greenfinch (12.57\%), Yellow-throated bunting $(7.54 \%)$ and so on. These 4 species occupy $81.11 \%$ of the total individuals sighted in this area.

In October several species of transients such as Chestnut bunting and Dusky thrush, arrive in this area, which make the number of species observed in this area larger than that in November. The comparatively large number of individual birds in October is due to large flocks of Chestnut bunting sighted in October.

The plot census records 11 species with 183 individuals in October and 14 species with 159 individuals in November in its area. The most dominant species in October is Siskin (38.80\%), followed by Great tit (16.94\%), Brambling (14.75\%), Yellow-throated bunting $(8.74 \%)$ and so on. These 4 species occupy $79.23 \%$ of the total individuals sighted in this area. In November, Brambling (24.52\%) is the most dominant species, followed by Siskin (22.64\%), Great tit (14.46\%), Grey starling (13.83\%) and so on, these 4 species being the dominant species in this area.

That more species were sighted in November than in October is due to the frequent observations of the wandering flight of bird species such as Black kite, Goshawk, Grey starling, Brown-eared bulbul, and Dusky thrush in November. And, that more individual birds were sighted in October than in November is due to an increase in the number of individual birds such as Siskin, Great tit and Yellow-throated bunting that were sighted in October. This kind of difference in the number of birds sighted would be eliminated by repeated censuses in the same area. 
Thus, both in the line transect and the plot censuses, dominant species are invariably Siskin, Great tit and so on. Chestnut bunting and Brambling show seasonality in October and Novemver, respectively. However, repeated censuses would show that residents such as Greenfinch and Yellow-throated bunting are dominant species as well.

Summary : 1. As appears in Tables $1-2$, the number of species and individual birds sighted in the census generally shows a decreasing tendency as the census was progressing from Seocheon area where the forest is suffering a severe damage by pine needle gall-midges, through Kochang area where forests are suffering an average affliction, to Muan area which suffered a severe forest damage but it now much recovered from the affliction.

In each of these areas, more species and individuals of birds are sighted in a red pine forest than in a black pine forest. In general, more species of birds are sighted in October than in November because of the arrival of transients, while in November large flocks of a few species of winter visitors arrive in the census areas for wintering showing a high population density.

2. Typically dominant species in the census areas are the 6 species of permanent residentsGreat tit, Jay, Turtle dove, Crow tit, Yellow-throated bunting and Greenfinch; the 3 species of winter visitors-Siskin, Brambling and Golderest; and several species of transients such as Dusky thrush, Tristram's bunting and Chestnut bunting. These dominant species of birds have a feeding activity closely related to pine needle gall-midges. A survey of insectivorous birds previously conducted by Ko et al. in 1969 reports that the majority of these bird species feed on pine needle gall-midges also.

3. Jay is dominant in red pine forests and Greenfinch is dominant in black pine forests.

4. Early morning plot censuses usually sight more species and individual birds than plot census carried out later in the morning.

\section{References}

Forest Research Institute 1973. The infliction of pine needle gall-midge in major areas. Forest Prevention 6(9) : 19-21.

Kendeigh, S.C. 1947. Bird population studies in the coniferous forest biome during a spruce budworm outbreak. Dept. Lands and For. Canada, Biol. Bull. 1: 1-100.

Ko, J.H. et al. 1969. The bird as a vertebrate predator of the larvae of pine gall-midge, Thecodiplosis japonensis Uchida et Inouye. Jour. Kor. For. Soc. (9) : 49-54.

Kuroda, N. and K. Ogasawara 1967. A survey in Kinka Mountain in Miyagi-ken in 1966. JIBPCT-SE : 158-179. Tokyo.

Turcek, F.J. 1949. The bird population in some deciduous forests during a gypsy moth outbreak. Bull. For. Res. Czecoslov. Repub. 3: 108-131.

Williamson, K. 1969. Bird communities in woodland habitats in Wester ross, Scotland. Jour. Forestry 63(4): 1-24.

Won, P.O. and M. B. Yoon 1971. Report on the scientific survey of Woollung-do (Dagelet island): Birds : 63-78. Bureau of Cultural Property, MOCI, Seoul.

Won, P. O. and M. B. Yoon 1972. A survey of birds at the national park of Mt. Sokri, 56 pp. Inst. Orni., Kyung Hee Univ., Seoul. 


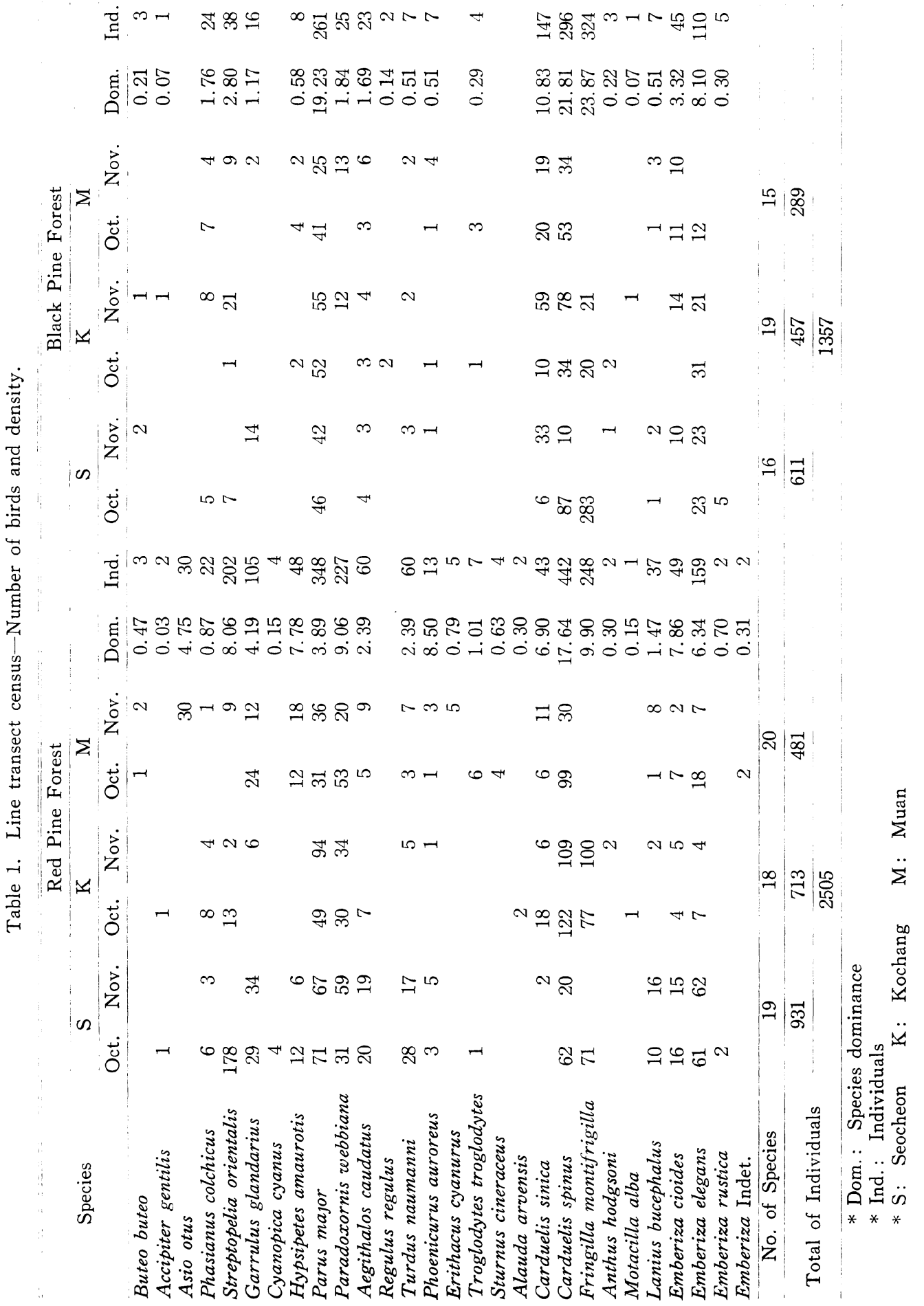

(107) 


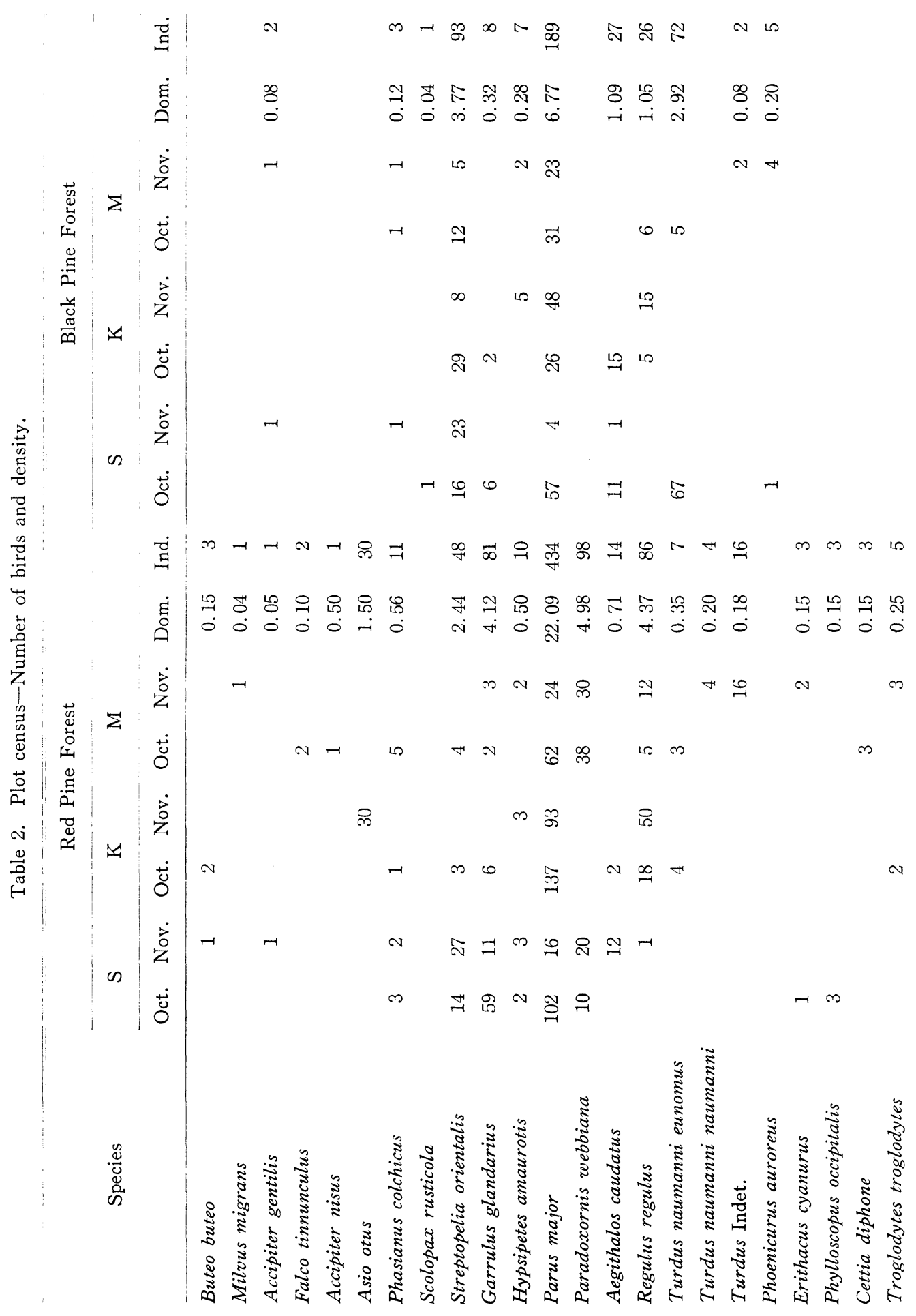




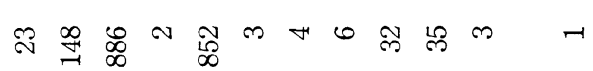

Љ

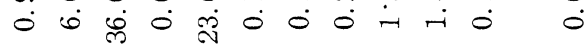

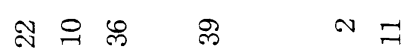

の츠

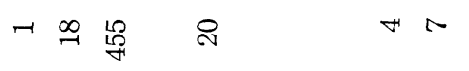

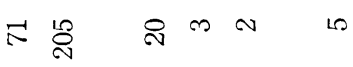

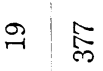

$\infty 18$ ก

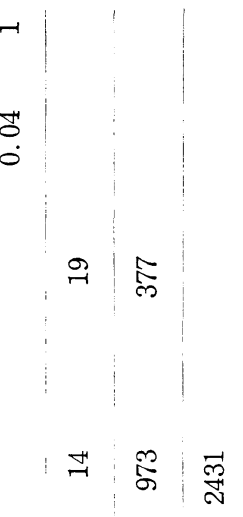

的落

$\stackrel{\Xi}{\exists} \exists$

○

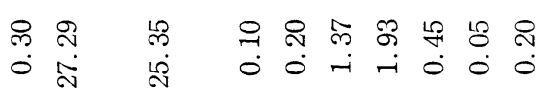

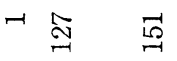

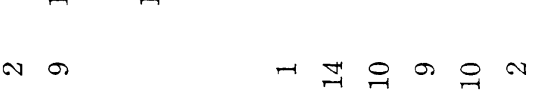

$\underset{N}{\infty}: \infty$
요
$\infty$

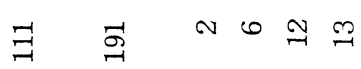

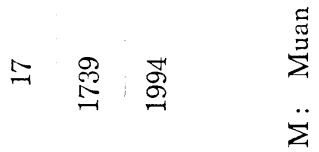

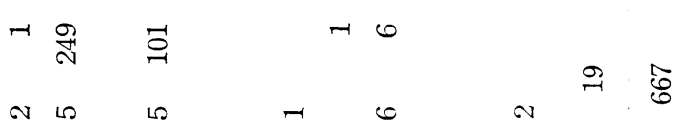

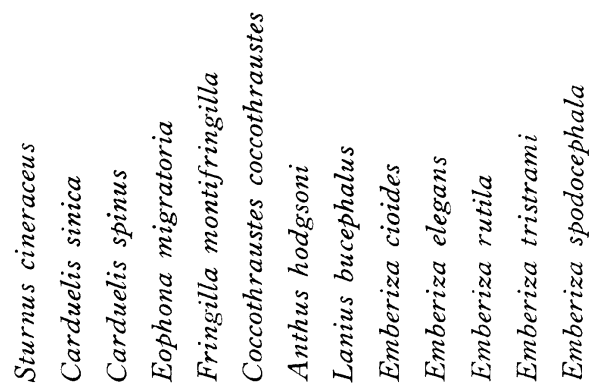

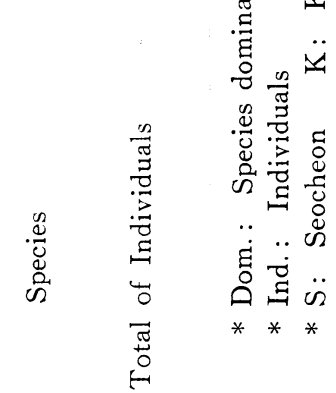




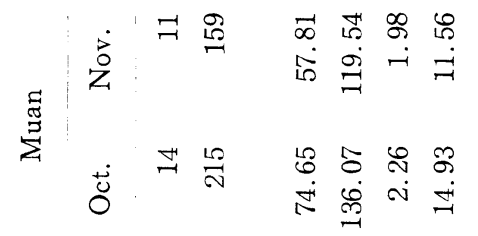

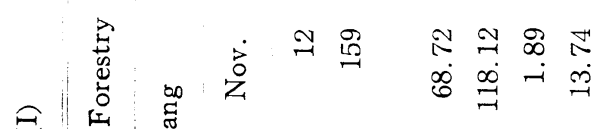

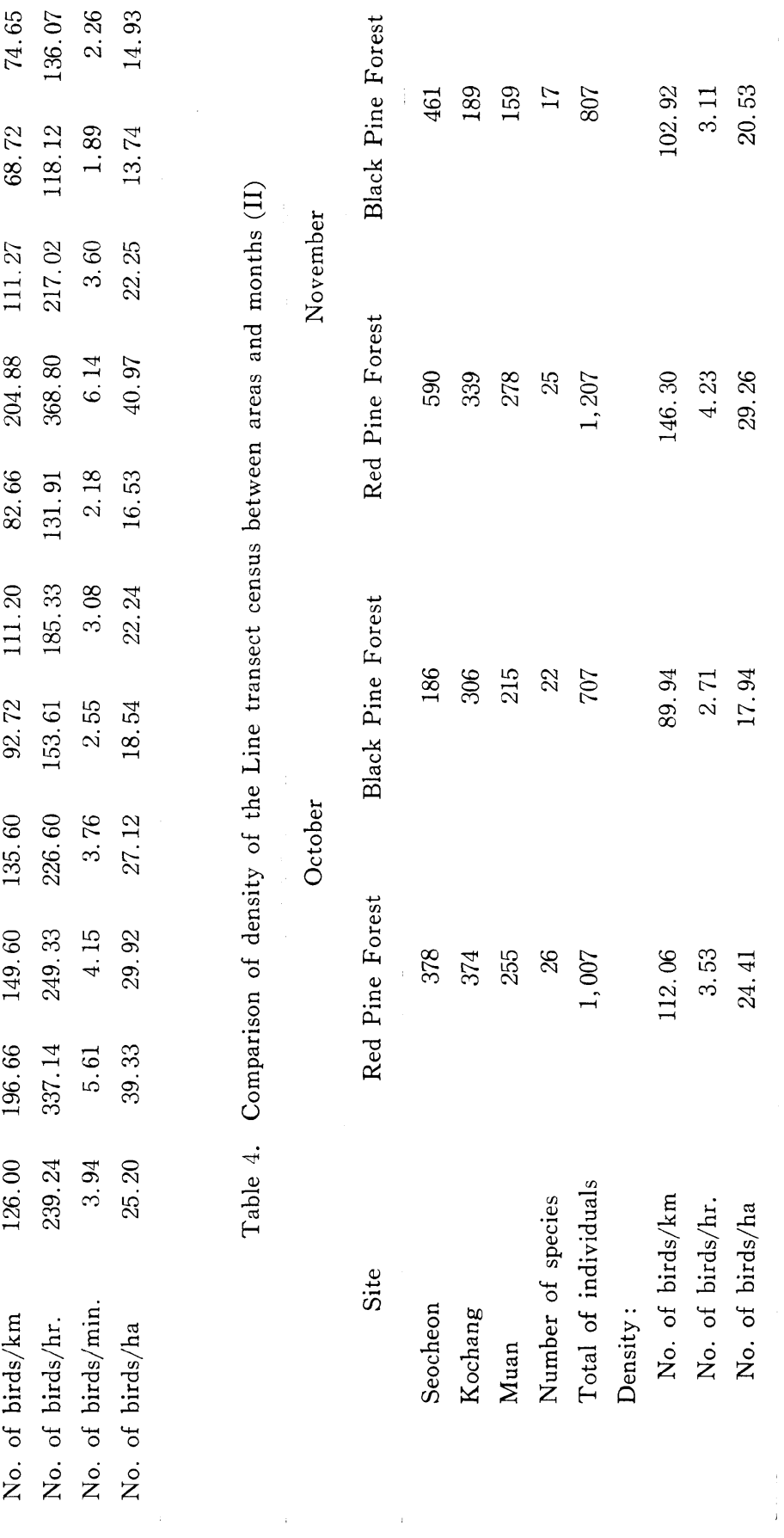

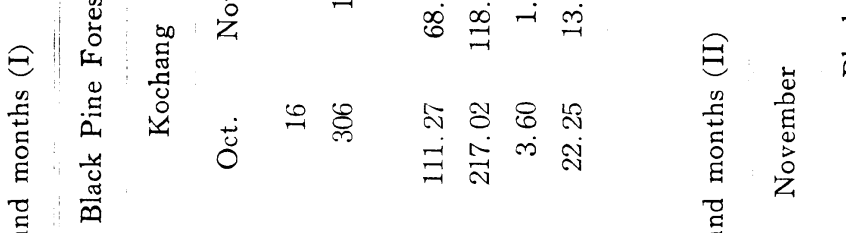

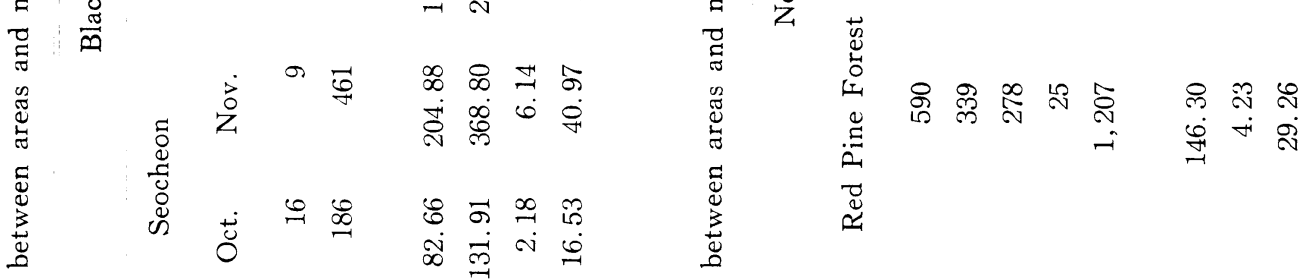

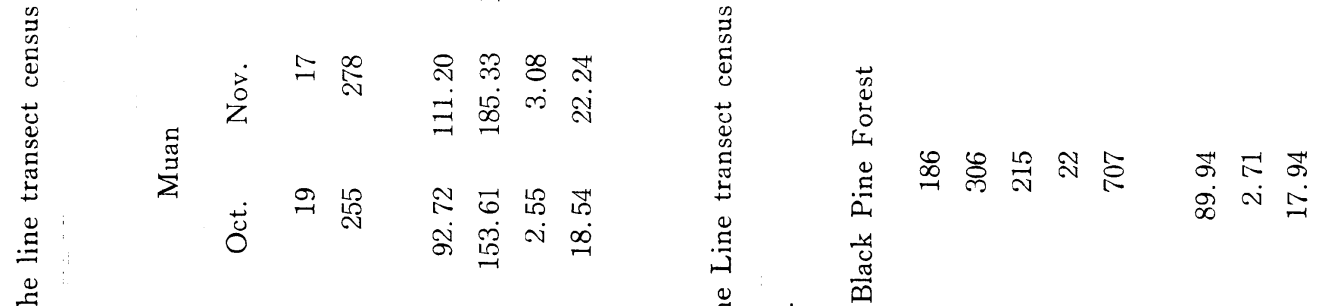

$$
\begin{aligned}
& \frac{ \pm}{ \pm}
\end{aligned}
$$

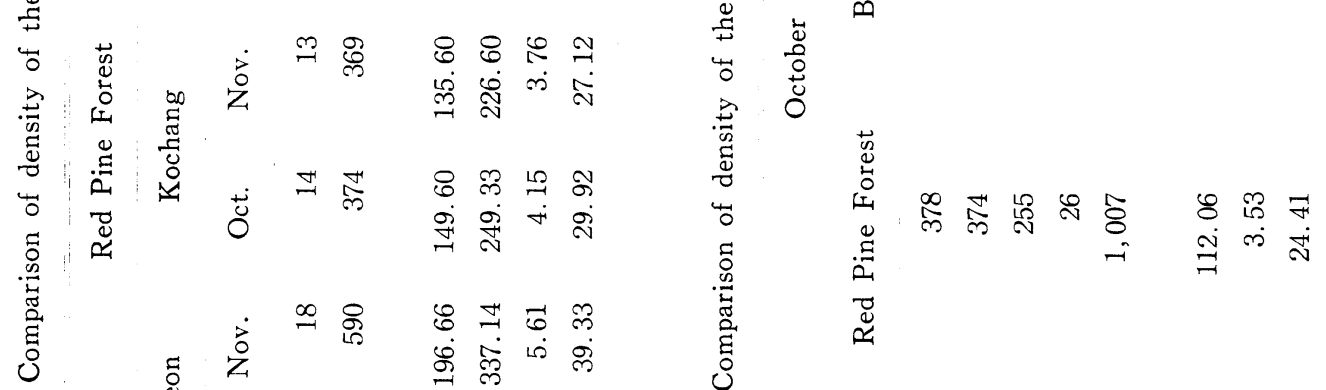

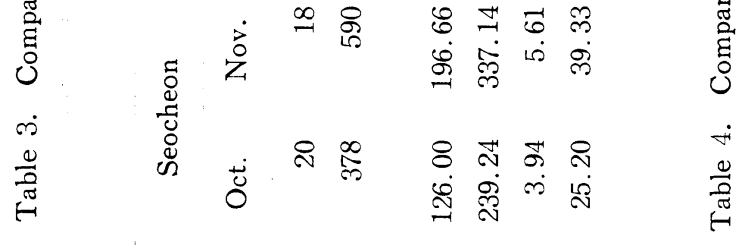

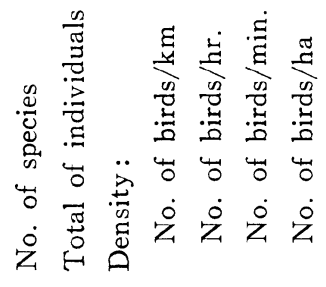




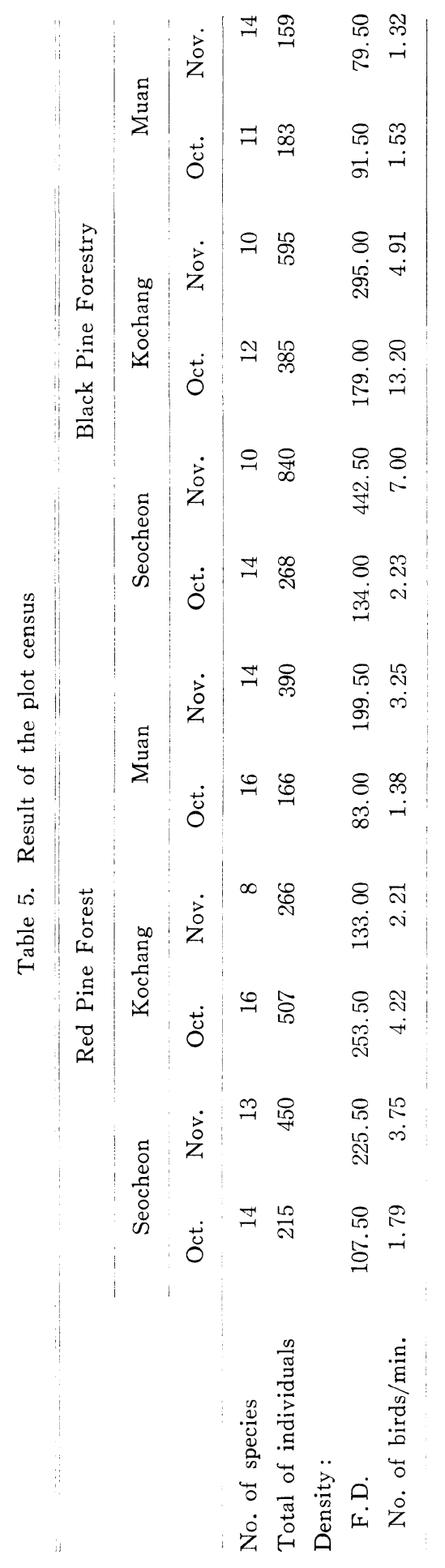

